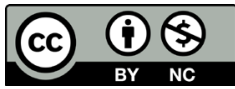

Licenciado sob uma licença Creative Commons

ISSN 2175-6058

DOI: http://dx.doi.org/10.18759/rdgf.v20i3.1777

\title{
DIREITO, LITERATURA E EXTENSÃO: ANÁLISE DO PROJETO QUINTA LITERÁRIA DA UNIVERSIDADE DE FORTALEZA COMO CONTEÚDO CURRICULAR À LUZ DA RESOLUÇÃO CNE/CES № 7/2018 E DO PARECER № 635/2018
}

\author{
LAW, LITERATURE AND EXTENSION: ANALYSIS OF THE \\ THURSDAY'S LITERARY PROJECT OF THE UNIVERSITY OF \\ FORTALEZA AS A CURRICULAR CONTENT UNDER RESOLUTION \\ CNE/CES No 7/2018 AND OPINION No 635/2018
}

\author{
Lívia Chaves Leite \\ Érica Valente Lopes \\ Monica Mota Tassigny
}

\section{RESUMO}

Analisa-se em que medida o ensino do Direito associado à Literatura auxilia no desenvolvimento do raciocínio crítico-reflexivo do discente, por intermédio da inclusão do Projeto de Extensão Quinta Literária (UNIFOR) na grade curricular. Busca-se aporte nas diretrizes estabelecidas no Parecer no 635/2018 e Resolução CNE/CES no 07/2018, editadas pelo Ministério da Educação. A metodologia será bibliográfica, documental, de campo opinativa, com abordagem qualitativa e caráter exploratório, aplicando-se questionário a alunos participantes do projeto no interregno de 2015 a 2019. Diante da constatada importância no desenvolvimento do pensamento reflexivo e crítico do graduando, propõe-se inseri-lo como disciplina curricular.

Palavras-chave: Direito e Literatura. Extensão Acadêmica. Resolução CNE/ CES no 07/2018. 


\section{ABSTRACT}

It is analyzed the teaching of law associated with literature helping the development of the student's critical-reflexive thinking through the inclusion of Thursday's Literary Extension Project (UNIFOR) inside curriculum. It seeks to be based on the guidelines established in Opinion 635/2018 and CNE/CES Resolution 07/2018, issued by the Ministry of Education. Methodology will be bibliographic, documentary, opinionated, with qualitative approach and exploratory character, applying questionnaire to students participating in the project from 2015 to 2019 . Given the notice importance in the development of reflective and critical thinking of the student, it is proposed to insert it as a curriculum subject.

Keywords: Law and Literature. Academic Extension. CNE / CES no 07/2018.

\section{INTRODUÇÃO}

A reflexão teórico-acadêmica sobre o ensino do Direito vê-se instada a enfrentar novos paradigmas. A universidade, como um espaço privilegiado de debate e reflexão, tem papel primordial nesse processo. Tendo em vista as discussões acerca do ensino jurídico no século XXI e a compreensão da necessidade de sua reformulação, metodologias alternativas de ensino são buscadas, dentre as quais o Direito associado à Literatura, que ora se pretende analisar, sob o ponto de vista da extensão universitária e sua inclusão curricular.

Nesse sentido, a Constituição Federal de 1988 traz, em seu art. 2071, o princípio da indissociabilidade entre as três dimensões da universidade, quais sejam: o ensino, a pesquisa e a extensão. Estas devem relacionarse harmonicamente, de modo a cumprir sua precípua finalidade de compromisso social e formação profissional do aluno. Nessa visão, o discente atua como protagonista de sua formação técnica, obtendo competências essenciais à sua formação profissional e social, donde emerge uma nova concepção de sala de aula, ultrapassando o limitado espaço tradicional de ensino-aprendizagem das universidades.

Nesse ínterim, insere-se a extensão universitária de modo que visa a ampliar o espaço de ensino para o ambiente extramuros, reconstruindo 
o processo histórico-pedagógico-social do discente, fazendo com que o estudante deixe de atuar passivamente como receptáculo de um conhecimento validado pelo educador para se tornar um elemento ativo no processo de ensino-aprendizagem.

Nessa perspectiva, o Ministério da Educação, por meio do Conselho Nacional de Educação, editou o Parecer no 635/2018 e a Resolução CNE/ CES no 07/2018, que, respectivamente, estabeleceram uma revisão das diretrizes curriculares nacionais do curso de graduação em Direito e a formulação de diretrizes para a extensão na educação superior brasileira. Dentre as diversas possibilidades e alternativas para aprimoramento do ensino jurídico, busca-se, neste trabalho, analisar em que medida o ensino do Direito associado à Literatura, na extensão universitária, contribui para a formação jurídica e humana do aluno, em razão das interfaces que se apresentam entre ambas as searas do conhecimento.

Faz-se imprescidível ir além do debate teórico, razão pela qual se escolheu o Projeto de extensão Quinta-Literária, da Universidade de Fortaleza, como objeto de análise da hipótese. Este existe desde o ano de 2011, com encontros mensais consistentes em leituras e reflexões de obras literárias com o objetivo de, ao final, levar o debate jurídico-literário tanto para discentes e docentes da própria universidade, quanto para escolas públicas municipais e estaduais.

De forma a fundamentar a pesquisa científica, utilizar-se-á metodologia de fonte bibliográfica, documental e de campo opinativa, por meio de formulário Google Forms, com abordagem qualitativa, pura e caráter exploratório, com o fito de responder aos questionamentos suscitados. Os formulários foram entregues por e-mail aos discentes participantes do referido programa de extensão, entre os anos de 2015 e 2019 e possibilitaram propor-se, ao final, a inclusão do projeto de extensão na matriz curricular do curso de Direito da Universidade de Fortaleza, não olvidando a possibilidade de expansão a outras instituições.

Isso porque o Direito, principalmente diante do cenário transdisciplinar e globalizado, é entendido, também, como meio de comunicação e de integração cultural, assim como a Literatura, que em igual modo pode ser considerada como elemento essencial para a construção do sentido social de comunidade, realizando um intercâmbio 
contínuo entre os dois campos. Funda-se, a partir dessa relação, um lugar distinto do lugar-comum jurídico que se busca transformar, sendo ele um espaço crítico por excelência.

\section{O ENSINO JURÍDICO NAS UNIVERSIDADES E A NECESSIDADE DE SUA REFORMULAÇÃO}

O ensino jurídico no Brasil, durante o período do Brasil-Império, era, em grande parte, reflexo do ensino ofertado pela Faculdade de Direito de Coimbra, de onde advinham os bacharéis que aqui atuavam. Tal situação ocorria em razão de os primeiros cursos de Direito só terem sido instituídos no início do século XIX, com a sanção da Carta de Lei, em 11 de agosto de 1827, que instituiu os cursos de Direito em São Paulo e Olinda (MARTÍNEZ, 2006, p. 02), os quais eram destinados aos interesses do setor economicamente dominante (NEVES, 2010, p.78).

Nesse contexto, pretendia-se, no Brasil, construir cursos de Direito com a finalidade de atender aos interesses de um Estado ainda em processo de consolidação de suas bases institucionais e estruturais. Por esse motivo, a obtenção do título de bacharel em Direito adquiriu um status social, diante da presença de inúmeros advogados na burocracia estatal, os quais formavam uma verdadeira elite social, portadora de prestígio, tornando-se, pois, objeto de desejo não somente da classe abastada, mas também das demais classes da população, que viam na faculdade de Direito uma possibilidade de ascensão social (CARVALHO, 2003, p. 86).

Viu-se, assim, iniciar uma democratização do ensino jurídico, com a consequente mobilidade de classes sociais e difusão de conhecimento. Essa expansão da via de acesso ao ensino superior deu-se, todavia, sem a presença de parâmetros para um ensino jurídico crítico e satisfatório à sociedade. À democratização do ensino jurídico, não se seguiu o aprimoramento da devida qualidade pedagógico-científica deste ensino (SPOSATO; SANTANA, 2018, p. 330), nem a devida articulação entre os órgãos, instituições e sistemas de ensino, dando ensejo a uma lacuna 
entre o ensino jurídico e as mudanças ocorridas na sociedade, inclusive na sua estrutura social, no decorrer dos anos (NEVES, 2010, p. 78).

A manutenção do método de ensino jurídico advindo da Faculdade de Coimbra passou a ser reiteradamente denunciado como não suficientemente capaz de responder às necessidades brasileiras desde, pelo menos, 1955, ano em que Santiago Dantas apresentou seu pioneiro: "A Educação Jurídica e a Crise Brasileira" (GHIRARDI; OLIVEIRA, 2016, p. 381). Os conteúdos e a reprodução de informação eram enaltecidos em detrimento da preocupação com a preparação de profissionais do direito e para o ensino do direito, aptos a dar conta das transformações políticas, jurídicas, econômicas e sociais nacionais e internacionais. 0 resultado foi uma disruptura do sistema de ensino jurídico (ESPINDOLA; SEEGER, 2018, p. 99).

Observou-se, doravante, um ensino positivista pautado em princípios e praxes obsoletas, dando ensejo a uma desarmonia do ensino do Direito diante dos novos rumos da sociedade. 0 ensino jurídico atual persiste na sua inadequação à realidade para a qual foi proposto, não cumprindo a função social da aprendizagem da ciência jurídica, pois o que se observa do ensino jurídico no século XXI é uma produtividade acadêmica em padrões industriais, em detrimento da busca de uma aprendizagem aprofundada da ciência. Trata-se de uma situação que, indubitavelmente, põe em risco a sua qualidade.

Nesse sentido, o Ministério da Educação, a partir das diretrizes curriculares do curso de Graduação em Direito ${ }^{2}$, estabeleceu que o curso deverá assegurar, no perfil do graduando: sólida formação geral, humanística e axiológica; capacidade de análise; domínio de conceitos e da terminologia jurídica; adequada argumentação; interpretação e valorização dos fenômenos jurídicos e sociais, aliada a uma postura reflexiva e de visão crítica que fomente a capacidade e a aptidão para a aprendizagem autônoma e dinâmica, indispensável ao exercício da Ciência do Direito, da prestação da justiça e do desenvolvimento da cidadania.

Os parâmetros determinados pelo Ministério da Educação tornaram-se utópicos diante da realidade do ensino jurídico. Observa-se o surgimento de um verdadeiro senso comum teórico, uma reprodução de verdades jurídicas (WARAT, 1995, p. 69), encobrindo seu pensamento 
crítico, obscurecendo a ciência jurídica, fazendo-se do Direito uma obviedade que dificilmente é questionada (STRECK, 2013, p. 14).

Sabe-se que, no cenário de globalização e de universalização, em que se convergem culturas, ideologias, conflitos e conhecimentos os mais diversos, não se pode considerar nada sob o prisma da certeza e da perpetuidade. Tudo se questiona, tudo requer novas respostas e novas soluções. 0 Direito, pois, como centro organizacional de uma sociedade, não se vê a salvo de tais movimentos (GHIRARDI, 2009, p. 02).

Se antes era possível dar respostas aos anseios científicos compartimentando as diversas áreas de estudos, hoje se torna indispensável uma visão que conjugue a multidimensionalidade dos saberes, a partir de uma mentalidade integrativa que venha propor uma reforma. (ESPINDOLA; SAGOI, 2017, p. 42).

Redimensionar e redefinir o Direito a partir de uma nova lógica implica mais do que uma reanálise de seus institutos, mas, sobretudo, a sua reestruturação como forma social e objeto científico, ante a crise dos modos de configuração de seu espaço de ensino. Ghirardi $(2009$, p.02) defende que a reflexão teórico-acadêmica sobre o Direito encontra-se compelida a enfrentar as novas tensões a partir de novos paradigmas. A universidade, como espaço privilegiado de debate, não pode deixar de se transformar neste processo.

Frente à necessidade de uma nova lógica na estrutura, na compreensão e na prática do Direito, soma-se a de reestruturá-lo enquanto objeto de estudo e de pesquisas científicas, mormente no âmbito acadêmico. 0 método tradicionalmente adotado nas universidades de Direito do país assume um caráter predominantemente teórico, com a excessiva memorização de artigos de leis, jurisprudências, entendimentos e divergências doutrinárias, desconectando o aluno do aspecto prático-profissional da disciplina. Há, pois, um claro divórcio entre a teoria e prática.

Ademais, para além de uma deficiência quanto ao ensino preparatório para a uma futura prática profissional, percebe-se que o ensino direcionado e pautado majoritariamente na teoria, no conhecimento e aplicação de códigos e de jurisprudência, também não favorece o desenvolvimento de outros aspectos indispensáveis ao operador do direito, como: criatividade, senso crítico, capacidade de 
intepretação, ampliação do horizonte de ideias, conhecimento de mundo, sensibilidade quanto às questões sociais etc.

Observa-se, assim, um modelo de ensino mecanicista, com a ausência de reflexão crítico-social-cultural e de embate cognitivo crítico do Direito, havendo uma predominância do positivismo exacerbado como norte para a metodologia de ensino, fomentando-se um ensino jurídico cada vez mais afastado da reflexão contextual sociocultural da norma jurídica. Essa metodologia apenas contribui para a manutenção de em sistema de ensino inteiramente legalista e dogmático, sem a devida promoção da conscientização e criticidade do aluno (BITTAR, 2013, p. 115).

Nesse sentido, os alunos são sobrecarregados por teorias, jurisprudências, textos de leis que, muitas vezes, de tão extensos e prolixos, são pouco compreendidos, tornando os alunos verdadeiros "leitores de carteirinha", o que, nem de longe, significa que estão a assimilar, de fato, algo. "Assim, sua cabeça é semelhante a um estômago e a um intestino dos quais a comida sai sem ser digerida", diz (SCHOPENHAUER, 2012, p. 22).

No mesmo sentido, Streck (2010, p. 335), ressalta que a docência acaba se configurando como uma transmissão rápida de conhecimentos consignados em manuais de fácil leitura, sendo esse um dos fatores que contribui para a fragilização do Direito. 0 ensino jurídico passa a ser tomado por uma cultura estandardizada, verificada nas doutrinas simplificadas e nos resumos plastificados, ambos carentes de uma discussão crítica e reflexiva.

Requer-se, dessa forma, que o operador do Direito saia de seu lugar-comum, afastando-se do senso comum teórico e dos positivismos reducionistas, resultado das formações jurídicas tradicionais; e ofereça uma nova matriz pedagógica e epistemológica para sua efetiva superação. Somente assim deixará de ser uma simples transmissão de conhecimentos para se tornar uma atividade ligada à pesquisa e extensão (GOMES; TASSIGNY, 2018, p. 170).

Diante desse cenário, percebe-se a necessidade de rompimento com o atual sistema de ensino e a busca por outras alternativas para 0 ensino jurídico, uma vez que o modelo adotado remonta ao pensamento racionalista do século XVIII (DUARTE; MADERS, 2016, p. 09). À medida que as demandas reclamam por soluções pautadas em novos valores 
e métodos, e que os conflitos se constroem de modo a acompanhar as relações a nível global, permeadas de inovações culturais, ideológicas e científicas, a sociedade clama por uma nova postura do jurista.

\section{ENSINO JUSLITERÁRIO COMO ALTERNATIVA AO MÉTODO TRADICIONAL}

Ante o cenário retratado do ensino jurídico no século XXI, pulsa a necessidade de repensá-lo, com destaque à importância do estudo interdisciplinar entre o Direito e a Literatura. A partir desse cruzamento de caminhos, funda-se um espaço crítico em expansão, permitindo aos juristas assimilar a capacidade criadora, crítica e inovadora da Literatura e, assim, superar as barreiras colocadas pelo sentido comum teórico, reconhecendo a importância do caráter construtivo da linguagem no interior dos paradigmas da intersubjetividade e intertextualidade (TRINDADE, 2012, p. 01).

Godoy (2008, p. 41) aponta como pais fundadores dos estudos associados do Direito e da Literatura: John Henry Wigmore, Benjamin Nathan Cardozo e Lon Füller. Nos Estados Unidos, o movimento Law and Literature cujo início se deu nos anos 70, surgiu com o intuito de uma maior utilização de elementos literários na análise do Direito. Conquanto alguns juristas já houvessem percebido a interconexão entre as duas searas do conhecimento, foi o Law and Literature Movement que impulsionou os estudos da Literatura e do Direito, sistematizando e organizando seu método próprio. 0 movimento conseguiu surtir repercussão no Velho Continente e nos países anglo-saxões, mas ainda resta desapercebido na cultura jurídica brasileira (SCHWARTZ; MACEDO, 2008, p. 1019).

No Brasil, desde o século XVII, inúmeros são os literatos com formação jurídica. Nomes como José de Alencar e Rui Barbosa são famosos por seus escritos literários, bem como pela atuação jurídica. Nesta senda, inúmeros clássicos da literatura brasileira contêm em seus textos questões importantes do ponto de vista jurídico, podendo-se citar 
exemplos como Jorge Amado (Capitães da Areia) e Graciliano Ramos (Vidas Secas).

Consoante Trindade e Bernsts (2017, p. 236), um marco histórico na evolução dos estudos em Direito e Literatura no Brasil foi a publicação, em 2005, da edição em português da obra "Contar a Lei: as Fontes do Imaginário Jurídico”, de François Ost. No prólogo de sua obra (OST, 2009, p. 07), o autor afirma que o jurista é o poeta por excelência, sendo sua maneira de fazer poesia: a narração dos fatos. 0 jurista é, portanto, um empírico por formação e um literato por vocação.

Dessa sorte, a conjunção com a Literatura pode ser vista como uma prática ainda nova para parte dos juristas brasileiros, inclusive para a comunidade acadêmica. Entretanto, as incursões promovidas nesse campo de investigação perfazem uma tradição centenária, visto que atravessam a história do século XX, sobretudo no cenário internacional (TRINDADE; BERNSTS, 2017, p. 230).

Vera Chueri, em seu Dicionário de Filosofia do Direito (2006, p. 233), afirma que a junção do Direito à Literatura é um campo novo de alternativas para questões formais e materiais que afligem tanto um como o outro, sendo essa relação, ao nível metodológico, não só concebível como desejável. Para uma melhor ilustração, pode dizer respeito tanto ao estudo de temas jurídicos na Literatura, como à utilização de práticas da crítica literária para compreender e avaliar o Direito.

A importância do cinema, da poesia e da literatura são indubitáveis para uma renovação do ensino jurídico, uma vez que não se limitam a analises gramaticais, sintáticas ou semióticas, mas buscam uma maior expressão do homem nas suas relações e experiências, incitando descobertas de si próprio e da complexidade da sociedade.

Nesta senda, considerando o caráter de criticidade da obra literária, há que se levar em conta que ela é uma obra de arte, repleta de enigmas e inquietantes estranhezas, que são capazes de contestar o óbvio, afastar aquilo que é dado como verdade, dissolver as certezas e romper convicções. A obra de arte produz, num processo criativo, um deslocamento no olhar, uma ampliação e fusão dos horizontes, de tal maneira que, por intermédio dela, o real possibilita que surjam mundos e situações, até então, não imaginados (TRINDADE, 2012, p. 03). 
Ademais, os horizontes de sentido, abordados por Hans-Georg Gadamer (2003, p. 243), possibilitam que o indivíduo se utilize de seus conteúdos de consciência, de suas experiências na estruturação e na significação que juntos resultam na sua atuação como leitor, pressupondo compreensão e interpretação de todo o contexto sociocultural ao seu redor, concretizando-se no eixo da intersubjetividade. Heidegger (1973, p. 347), em consonância, aduz que a linguagem é a morada do ser.

Nesse viés cognitivo da Literatura como arte, uma obra de arte não parte do zero, assim como o Direito precisa de informações outras que vão além da norma jurídica para proferir uma decisão. Novas formas revelam novos sentidos, aquilo que, conforme Ost (2002, p. 35) adormecia na memória coletiva. 0 Direito é, portanto, uma criação contínua, um romance cujo enredo não possui um final único e sim um último "contador", menciona o filósofo Dworkin (2017, p. 237). Nessa perspectiva, Warat (2004, p. 187), aduz que juntar o Direito à poesia é um protesto contra a mediocridade da mentalidade erudita, é recriar o homem provocando-o para que procure pertencer-se por inteiro, para que sinta aversão à uma racionalidade puramente objetivista.

Assim, dentre vários outros estímulos à expansão dos estudos jusliterários, como seminários e grupos de pesquisa na área, três acontecimentos, em especial, deram uma guinada para sua visibilidade e aprofundamento. 0 primeiro, a criação do Grupo de Trabalho "Direito e Literatura", no XVI Congresso Nacional do CONPEDI, em novembro de 2007, Belo Horizonte. 0 segundo, a criação, em 2008, do programa televisivo "Direito \& Literatura" cuja produção e apresentação ficou a cargo de André Karam Trindade e Lênio Streck, respectivamente. Em terceiro lugar, a criação da Rede Brasileira de Direito e Literatura (RDL), sociedade científica responsável pela realização do Colóquio Internacional de Direito e Literatura (CIDIL) e pela publicação da Anamorphosis, Revista Internacional de Direito e Literatura (TRINDADE; BERNSTS , 2017, p. 237-247).

Ressimbolizar o direito, assumindo-o como uma ciência da compreensão e não como ciência da explicação, superando o peso do paradigma liberal-iluminista e do pensamento linear-cartesiano, ainda tão presentes no nosso dia-a-dia, é um desafio que se busca, por 
intermédio de novas lentes pelas quais se possa enxergar o ensino jurídico (ESPINDOLA; SANGOI, 2017, p. 53).

Assim, a Literatura é uma das principais alternativas para a construção de um pensamento crítico, por intermédio da transdisciplinariedade. Uma de suas potencialidades é explorar o valor moral do jurista e sua humanização, tornando-o mais aberto e compreensivo às questões morais e sociais. Não é que a literatura transforme as pessoas, mas ela tem o condão de incrementar a capacidade de percepção, de imaginação, de pensamento crítico-reflexivo e, consequentemente, de humanização do leitor.

\section{UNIVERSIDADE E EXTENSÃO: RESOLUÇÃO CNE/CES № 07 DO MEC E PARECER № 635/2018}

Nesse contexto, a Constituição Federal de 1988 estabelece, em seu artigo 207, que as universidades obedecerão ao princípio da indissociabilidade entre ensino, pesquisa e extensão. Define, pois, as três dimensões da universidade que devem estar ligadas e equilibradas para que cumpram com seus fins de formação e compromisso social.

0 princípio da indissociabilidade reafirma a extensão universitária como processo acadêmico. No que se refere à relação entre a extensão e o ensino, observa-se a oportunidade de atribuir-se ao estudante o papel de protagonista na sua formação técnica, processo de obtenção de competências necessárias à atuação profissional e à formação como cidadão, que lhe permite se reconhecer como agente de garantia de direitos , deveres e de transformação social (BRASIL, 2018, p. 09).

Desse modo, em cumprimento à Lei no $13.005 / 2014$, a qual aprovou o Plano Nacional de Educação, vigente de 2014 à 2024, conforme disposto no artigo 214 da Constituição Federal, o Ministério da Educação, por meio do Conselho Nacional de Educação/Câmara de Educação Superior, editou Parecer no 635/2018 e Resolução CNE/CES no 07/2018, que estabeleceram uma revisão das diretrizes curriculares nacionais do curso de graduação em Direito e diretrizes para a extensão na educação superior brasileira, respectivamente. 
Até então, as diretrizes curriculares eram regulamentadas pela Resolução CNE/CES no 9, de 29 de setembro de 2004. Objetivou-se, com isso, atender as expectativas de parte da academia e de setores que representam a atuação profissional da área, assim como a necessidade de reajuste da estrutura destes cursos ao atual momento histórico, considerando as perspectivas do país no que diz respeito ao desenvolvimento da sociedade e à sua presença no contexto global.

Diante dos desafios impostos à educação superior no Brasil, advindos de processos de desenvolvimento de habilidades e competências, definição de estratégias curriculares, perspectivas de inserção no mercado de trabalho e bem-estar social; estabelece-se a necessidade de uma periódica reavaliação das diretrizes curriculares dos cursos de educação superior, a fim de que estimule a formação de competências e habilidades dos discentes.

O Parecer no $635 / 2019$ oportunizou o processo de elaboração das novas diretrizes curriculares nacionais do curso de Direito e contou com amplo debate junto aos órgãos de representação profissional, bem como de especialistas e representantes governamentais do campo da educação. Elas buscam implementar, no Projeto Pedagógico dos cursos de Direito, estratégias de articulação dos saberes e metodologias ativas de conhecimento, com integração entre teoria e prática, com a criação de uma relação de ensino-aprendizagem que atenda a um processo de construção de autonomia, de forma pluridimensional, dos pilares do conhecimento: aprender a conhecer, aprender a fazer, aprender a conviver e aprender a ser (BRASIL, 2018, p. 09).

Prevê, ademais, a explicitação das cargas horárias das atividades didático-formativas e da integralização do curso, a demonstração das formas de realização da inter e da transdisciplinariedade, a fim de que se possa garantir um aprendizado capaz de enfrentar os problemas e os desafios impostos pelo constante processo de inovação pelo qual passa o mundo, a produção de conhecimento e o espaço de trabalho que provoca o profissional do Direito.

Destarte, as Diretrizes Curriculares, ao destacarem a preocupação com um processo de aprendizagem que garanta autonomia intelectual ao aluno, que valorize a utilização de metodologias ativas, e que destaque a 
importância de formação de competências e habilidades, preocupam-se em construir critérios que possam provocar os cursos de Direito para uma formação inovadora, que garanta excelência e consiga responder aos novos desafios que são apresentados todos os dias por uma sociedade cada vez mais complexa.

Nesse sentido, a Resolução CNE/CES no 07/2018 estabeleceu as Diretrizes para a Extensão na Educação Superior Brasileira, que define os princípios, os fundamentos e os procedimentos que devem ser observados no planejamento, nas políticas, na gestão e na avaliação das instituições de educação superior de todos os sistemas de ensino do país. Ademais, regulamentou as atividades acadêmicas de extensão dos cursos de graduação, na forma de componentes curriculares para os cursos.

0 art. $3^{\text {o3 }}$ da Resolução CNE/CES no 07/2018 afirma que a extensão é a atividade que se integra à matriz curricular e à organização da pesquisa, constituindo-se em processo interdisciplinar, político educacional, cultural, científico e tecnológico, que promove a interação transformadora entre as instituições de ensino superior e os outros setores da sociedade, por meio da produção e da aplicação do conhecimento, em articulação permanente com o ensino e a pesquisa.

Desse modo, surge um novo conceito de sala de aula, não se limitando mais ao espaço físico tradicional de ensino-aprendizagem, compreendendo, portanto, todos os espaços, intra ou extramuros, em que se apreende e se (re)constrói o processo histórico-social em suas múltiplas dimensões e facetas. 0 eixo pedagógico tradicional "estudante/professor" é substituído pelo eixo "estudante/professor/comunidade". 0 estudante e a comunidade, na qual se desenvolve a ação de extensão, deixam de ser meros receptáculos de um conhecimento validado pelo professor para se tornarem participantes do processo (BRASIL, 2018, p. 09).

Objetivando uma produção de conhecimento, a extensão universitária sustenta-se em metodologias participativas e dinâmicas, dando ênfase em métodos de análise inovadores, constituindo aportes decisivos para a formação do aluno, tanto pela ampliação do universo de referência que ensejam, quanto pelo contato com as grandes questões contemporâneas que possibilitam, de algum modo, a reflexão sobre assuntos em voga (BRASIL, 2018, p. 10). 
Outrossim, as atividades de extensão, devem compor, no mínimo, $10 \%$ (dez por cento) da carga horária curricular estudantil dos cursos de graduação, as quais deverão, doravante, compor a matriz curricular dos cursos. Os Projetos Políticos Pedagógicos (PPPs) dos cursos de graduação devem ressaltar o valor das atividades de extensão e permitir aos alunos a obtenção de créditos curriculares ou carga horária equivalente após a devida avaliação. Tais previsões encontram-se expressas nos artigos 4ํㅜ e $14^{5}$ da Resolução CNE/CES no $07 / 2018$.

Diante das profundas alterações por que passa o Direito, como diretriz da ordem social, e com base no novo marco regulatório do ensino superior nas universidades, urge um novo lugar para o Direito como construção cultural, redesenhando-se as expectativas em relação ao profissional do Direito cuja atuação exige proficiência em uma ampla gama de saberes não imediatamente atrelados a noções de formação jurídica mais tradicionais (GHIRARDI, 2009, p. 06).

E é nesse sentido que se objetiva repensá-lo através de uma prática pedagógica interdisciplinar ainda pouco comum na cultura brasileira, por meio de estudos jusliterários, nos quais a Literatura, a partir de seu caráter plurissignificativo, vem propor um repensar no modo de compreender e de viver o Direito, configurando, mormente, uma metodologia ativa e alternativa a ser buscada nas atividades de extensão das universidades brasileiras.

Assim, a Universidade de Fortaleza - UNIFOR, por meio do seu projeto de extensão Cidadania Ativa e do Programa Quinta Literária, intercruzou os estudos jurídicos e literários, dando a oportunidade de os alunos estudarem o Direito sob uma nova matriz pedagógica e epistemológica, conforme se verá adiante. 


\section{OS ESTUDOS JUSLITERÁRIOS DE EXTENSÃO COMO CONTEÚDO CURRICULAR: UMA ANÁLISE A PARTIR DO PROJETO QUINTA LITERÁRIA DA UNIVERSIDADE DE FORTALEZA - UNIFOR}

Criado em 2001, o Programa Cidadania Ativa (PCA) é uma ação de extensão do curso de Direito da Universidade de Fortaleza, ligado ao Centro de Ciências Jurídicas (CCJ) que desenvolve projetos voluntários de responsabilidade social e ambiental em comunidades, e busca, principalmente, a conscientização dos direitos e deveres do cidadão e a prática da cidadania. O PCA participa também da Semana de Responsabilidade Social ${ }^{6}$.

0 programa constitui uma forma inovadora para integrar os corpos docente e discente da Universidade no desenvolvimento voluntário de atividades voltadas à conscientização de direitos nas comunidades, além da intervenção direta na execução de projetos especiais e do desenvolvimento de políticas públicas para governos e instituições não governamentais.

Outro intuito do programa é oportunizar ao cidadão beneficiado a transmissão do conteúdo aprendido a mais pessoas, por meio de atividades como palestras, visitas, distribuição de panfletos, cartilhas, dentre outros. Podem participar alunos de qualquer curso ou professores da Universidade que desejem ser orientadores voluntários, existindo inúmeros projetos em andamento.

Dentre eles, encontra-se o Quinta Literária, que surgiu em fevereiro de 2011, tendo como objetivo discutir clássicos da literatura nacional e internacional adentrando no âmbito do Direito. Com três edições por semestre, este busca fazer a ponte entre o Direito e a Literatura, com maior objetivo em incitar uma provocação, instigar com que os alunos se interessem pela leitura e obtenham os benefícios daí advindos.

O Projeto já analisou variadas obras, como por exemplo: "A Jangada de Pedra”, de José Saramago, “Grande Sertão: Veredas”, de João Guimarães Rosa, “Capitães da Areia”, de Jorge Amado, “O Alienista”, de Joaquim Maria Machado de Assis, "A Senhora”, de José de Alencar, "O nome da Rosa”, de 
Umberto Eco, "Hamlet”, de William Shakespeare, "Dom Quixote”, de Miguel de Cervantes e "O Conto da Aia", da escritora canadense Margaret Atwood.

\section{ANÁLISE DO PROJETO QUINTA LITERÁRIA DA UNIVERSIDADE DE FORTALEZA}

No objetivo de embasar a hipótese suscitada, realizou-se pesquisa de campo no formato pesquisa-ação, de caráter exploratório e abordagem qualitativa. Formulários produzidos na plataforma Google Forms foram enviados via e-mail, ao conjunto universo de 60 (sessenta) discentes participantes ou ouvintes do Programa Quinta Literária na Universidade de Fortaleza- Unifor, compreendendo o interregno de 2015 à metade do primeiro semestre de 2019.

A pesquisa, de cunho opinativo, respalda-se na Resolução no 466 de 12 de dezembro de 2012, do Conselho Nacional de Saúde, primando pelos objetivos éticos e pelo consentimento livre e esclarecido. Justificase a escolha do interregno de 2015 a 2019 por conta de mudança na estruturação interna do programa na Universidade de Fortaleza, tendo migrado do setor de Vice-reitoria para o Programa Cidadania Ativa em 2015 , somente iniciando o registro de dados dos alunos participantes a partir deste ano.

Após a formalização do requerimento, via e-mail, ao Programa de Cidadania Ativa, autorizou-se a entrega dos nomes e e-mails dos participantes do Projeto Quinta Literária de 2015 ao primeiro semestre de 2019. Dessa forma, confeccionou-se o formulário Google Forms com questões relacionadas ao objeto de pesquisa. 0 cerne do questionamento baseou-se em examinar em que medida o ensino do Direito associado à Literatura, na extensão universitária, contribui para a formação jurídica e humana do aluno. Como característica inerente à pesquisa-ação, indagouse também sobre imprescindibilidade da inclusão do Projeto Quinta Literária na matriz curricular da graduação em Direito na Universidade de Fortaleza, não se olvidando a expansão a outras instituições.

Para tanto, formularam-se perguntas, observando-se alta porcentagem, de forma a permitir inferir o posicionamento do discente 
frente à hipótese. Iniciou-se com as perguntas situacionais: (1) "Você é do Curso de Direito?"; (2) "Você participou do Projeto Quinta Literária ofertado como projeto de extensão na Unifor?”, para depois adentrar em questionamentos relacionados à formação social, à interação em grupo, como: (3) "Você acredita que o projeto o incentivou a ler mais?"; (4) “0 Projeto Quinta Literária o auxiliou no processo de interação em grupo?”; (5) "Você teve um maior contato com a realidade jurídica ou social por meio do projeto?", conforme exposto nos gráficos abaixo:

\section{Gráfico 1}

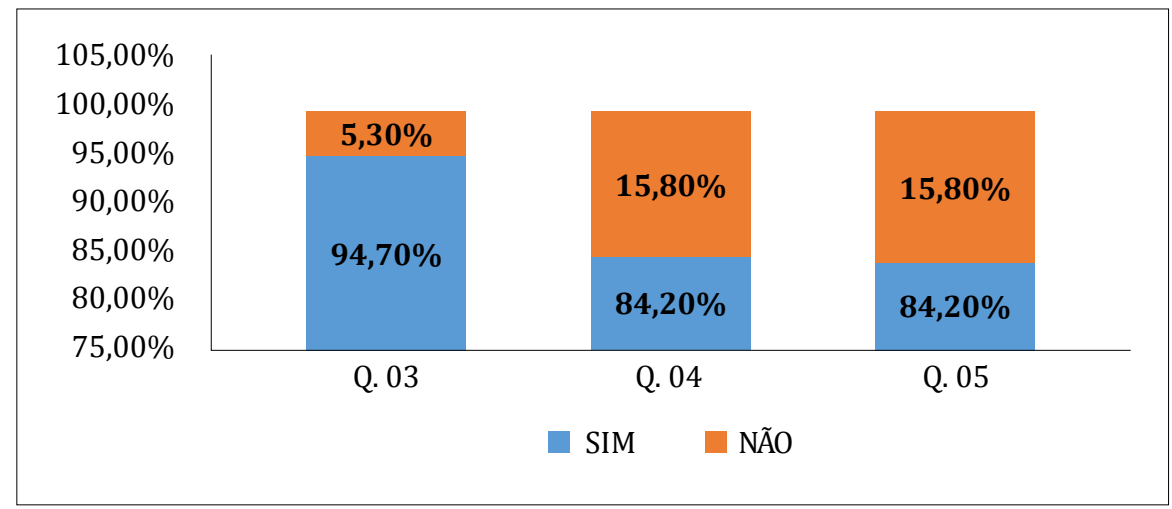

Fonte: Autoras

Em seguida, passou-se a indagações referentes à simbiose de conhecimento entre as ciências, como se pode ver nos questionamentos 6, 7 e 8 abaixo: (6) “Os ensinamentos obtidos no Projeto Quinta Literária o auxiliaram no desenvolvimento acadêmico durante o curso de Direito?"; (7) "Você acha que a experiência adquirida no Projeto Quinta Literária serviu como instrumento potencializador de seu senso crítico e raciocínio?"; (8) "Você acredita que o Direito associado à Literatura, por meio de projetos de extensão universitária, contribui para a formação jurídica e humana do aluno?". 


\section{Gráfico 2}

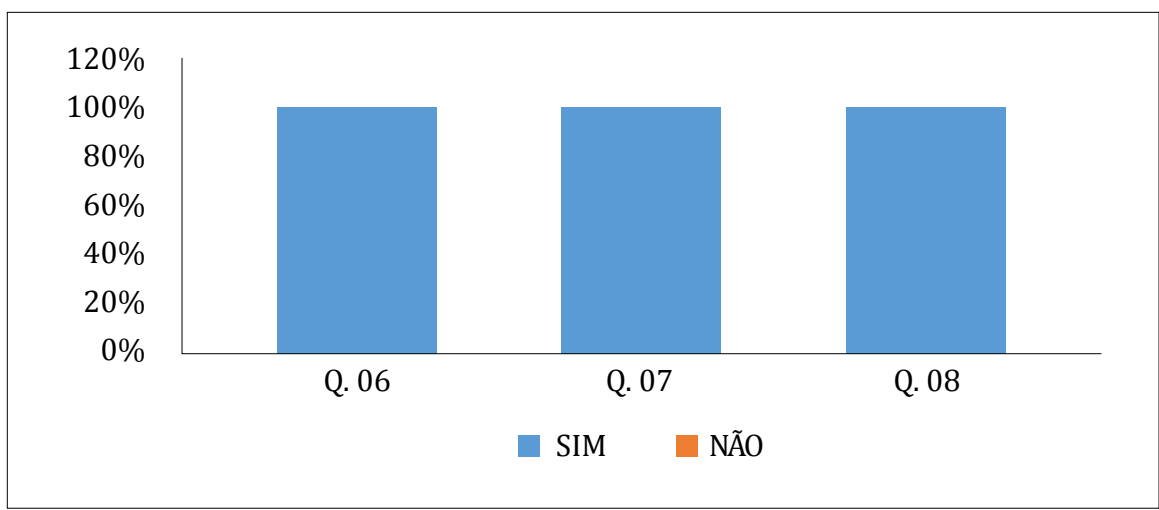

Fonte: Autoras

Assim como nas perguntas do gráfico retro exposto, quanto nas seguintes, observou-se o massivo posicionamento (100\%) permitindo a confirmação da hipótese ou, caso se prefira ser mais prudente, uma acentuada tendência ao questionamento central da pesquisa científica que ora se apresenta. Por fim, os alunos foram questionados sobre a importância da inclusão de projetos de extensão na grade curricular, com enfoque ao Projeto Quinta Literária e sobre aceitabilidade das mudanças trazidas pela Resolução CNE/CES no 7/2018, veja-se: (9) "Você acredita que é importante que as universidades incrementem o ensino jurídico a partir da inclusão de projetos de extensão na grade curricular?; (10) Você gostaria que o projeto de extensão Quinta Literária fosse contabilizado nos créditos disciplinares da grade curricular do curso de Direito?"; (11) A Resolução CNE/CES no 7/2018 estabeleceu que as atividades de extensão devem compor, no mínimo, 10\% da carga horária curricular estudantil dos cursos de graduação, integrando a matriz curricular. Você concorda?”. 


\section{Gráfico 3}

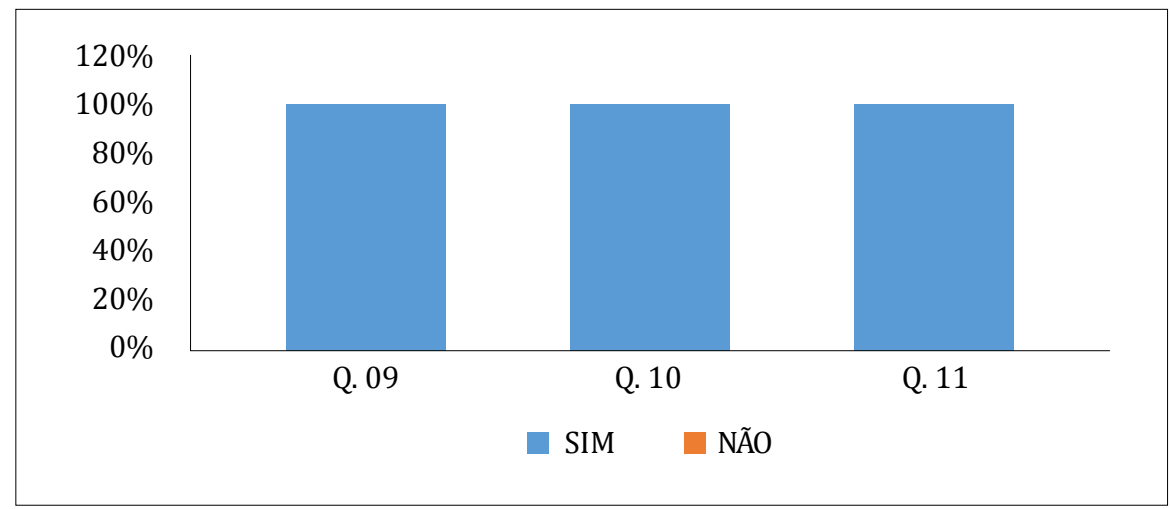

Fonte: Autoras

Dos 60 (sessenta) questionários enviados, 19 (dezenove) foram respondidos, dentre estes, 4 (quatro) retornaram por e-mail inexistente, permanecendo os restantes na livre opção em não responder. Contudo, conseguiu-se obter uma diretriz na análise suscitada. Há a tendência de confirmação da hipótese levantada, com indício positivo em maioria absoluta, mais de $50 \%$ das respostas colhidas, o que concede suporte ao que se proporá na subseção a seguir.

\section{PROPOSTA DE INCLUSÃO CURRICULAR}

Conforme delineado anteriormente, a Resolução CNE/CES no 07/2018 traz o redimensionamento das diretrizes e normas para as atividades de extensão no contexto da educação superior brasileira. Para que esses instrumentos imprimam qualidade na formação do estudante, as atividades extensionistas precisam possuir um projeto pedagógico que explicite alguns elementos essenciais, tais como: a designação do professor orientador, os objetivos da ação e as competências dos atores nela envolvidos, a metodologia de avaliação da participação do estudante.

A qualificação da formação do estudante, por meio de seu envolvimento em atividades extensionistas, depende também, no âmbito interno das instituições de ensino, de um diálogo perene e aberto dos órgãos, destinados ao fomento das atividades de extensão com os 
colegiados de gestão acadêmica da graduação e da pós-graduação, de forma que possibilite a aplicação efetiva das diretrizes de extensão e legislação vigente. Essa estruturação normativa, portanto, deve orientar a composição da grade curricular, levando em conta a correlação entre a carga horária e os créditos atribuídos, ou a previsão de cronogramas e regras disciplinares.

Diante desse pensamento de transformação social e, com base na publicação dos documentos mencionados pelo Ministério da Educação (MEC), a inserção do Projeto Quinta Literária na matriz curricular jurídica faz-se realizável. 0 princípio da transformação social reafirma a ação extensionista como o mecanismo pelo qual se estabelece a inter-relação da instituição de ensino superior com os outros setores da sociedade, com vista a uma atuação transformadora, voltada aos interesses e necessidades da maioria da população e propiciadora do desenvolvimento social e regional, assim como para o aprimoramento das políticas públicas.

Com base nos resultados colhidos, propõe-se a inserção do Projeto Quinta Literária na matriz curricular do Curso de Direito. Antes da edição do Parecer no 635/2018 e da Resolução CNE/CES nº 07/2018, isso não seria possível, pois o projeto é parte da extensão acadêmica, portanto, não integrante da grade curricular do ensino superior.

Com as diretrizes da extensão imiscuídas às do ensino, espera-se dar à essas atividades extensionistas as seguintes características: (i) privilegiar as questões sobre as quais se deve atuar, sem, no entanto, desconsiderar a complexidade e a diversidade da realidade social; (ii) oportunizar a vivência com situações que muitas vezes são relegadas ao segundo plano no estudo puramente jurídico; (iii) desenvolvimento de um pensamento reflexivo e crítico; (iv) ampliação dos horizontes de sentido e desenvolvimento humano; (v) efetividade na solução dos problemas. Todas essas características são potencializadas a partir de uma maior inserção do aluno no meio literário.

A experiência acadêmica no curso de Direito não pode se limitar, negligenciando a interação e a experiência com outros modos de interpretação da vida e da sociedade. A literatura deve ser compreendida como instrumento capaz de potencializar o criticismo, reflexão do 
intérprete e aplicador das normas, sendo sua inclusão na estrutura curricular uma contribuição na constante busca de renovação da ciência jurídica, de modo a evitar seu engessamento e superando a passividade de um aluno que, a partir de outros pontos de vista, tem a oportunidade de construir suas próprias convicções. Dessa forma, a pesquisa propõe que a associação do Direito à Literatura concretize-se no âmbito dos estudos dos graduandos do Curso de Direito.

\section{CONSIDERAÇÕES FINAIS}

Após a exposição do embasamento teórico, normativo e da pesquisa de campo opinativa, constituem-se subsídios a concluir o questionamento central do estudo, o qual é analisar em que medida o ensino do Direito associado à Literatura, na extensão universitária, contribui para a formação jurídica e humana do aluno sob a proposta de inserção do Projeto "Quinta Literária”, da Universidade de Fortaleza, na grade curricular de Direito.

Para tanto, executou-se pesquisa de campo opinativa, por meio de formulário, entregue aos alunos discentes durante o interregno de 2015 ao primeiro semestre de 2019 , contendo sucessivas perguntas duais, respostas afirmativas ou negativas para cada questionamento relacionado à temática do ensino de extensão, qualidade, proveito acadêmico, social e posicionamento quanto às recentes mudanças nas diretrizes de extensão acadêmicas pelo Ministério da Educação. 0 Formulário foi confeccionado na interface do Google Foms, enviado por e-mail e encontra-se no apêndice do artigo.

Por intermédio dos resultados colhidos, confirmou-se a hipótese, o que nos confere subsídio a propor a inclusão do projeto de extensão denominado "Quinta Literária" na matriz curricular de ensino da faculdade de Direito da Unifor, não olvidando a possibilidade de expansão a outras instituições, diante da abertura normativa do Conselho Nacional de Educação, Resolução CNE/CES no 7/2018, e do Parecer no 635/2018, o qual direcionou a inovação legal ao curso de Direito. 


\section{NOTAS}

1 Art. 207. As universidades gozam de autonomia didático-científica, administrativa e de gestão financeira e patrimonial, e obedecerão ao princípio de indissociabilidade entre ensino, pesquisa e extensão.

$\S 1$ ํ́ facultado às universidades admitir professores, técnicos e cientistas estrangeiros, na forma da lei.

$\S 2^{\circ} 0$ disposto neste artigo aplica-se às instituições de pesquisa científica e tecnológica.

2 Diretrizes Curriculares Nacionais do Curso de Direito foram estabelecidas pelo Conselho Nacional de Educação pela Resolução CNE/CES no 9, de 29 de setembro de 2004.

3 Art. $3^{\circ} \mathrm{A}$ Extensão na Educação Superior Brasileira é a atividade que se integra à matriz curricular e à organização da pesquisa, constituindo-se em processo interdisciplinar, político educacional, cultural, científico, tecnológico, que promove a interação transformadora entre as instituições de ensino superior e os outros setores da sociedade, por meio da produção e da aplicação do conhecimento, em articulação permanente com o ensino e a pesquisa.

4 Art. 4ํㅡㄹ As atividades de extensão devem compor, no mínimo, 10\% (dez por cento) do total da carga horária curricular estudantil dos cursos de graduação, as quais deverão fazer parte da matriz curricular dos cursos.

5 Art. 14 Os Projetos Políticos Pedagógicos (PPPs) dos cursos de graduação devem ressaltar o valor das atividades de extensão, caracterizando-as adequadamente quanto à participação dos estudantes, permitindo-lhes, dessa forma, a obtenção de créditos curriculares ou carga horária equivalente após a devida avaliação.

6 Disponível em: https://www.unifor.br/projeto-cidadania-ativa. Acesso em: 15.06.19.

\section{REFERÊNCIAS}

BITTAR, Eduardo Carlos Bianca. Curso de ética jurídica. 10.ed. São Paulo: Saraiva, 2013.

BRASIL. Constituição da República Federativa do Brasil. Brasília, DF, Senado, 1988. Disponível em: http://www.planalto.gov.br/ ccivil_03/Constituicao/Constituiçao.htm. Acesso em: 17 maio 2019.

BRASIL. Ministério da Educação. Resolução no 07, de 18 de dezembro de 2018. Estabelece as Diretrizes para a Extensão na Educação Superior Brasileira e regimenta o disposto na Meta 12.7 da Lei no 13.005/201. Disponível em: http://portal.mec.gov.br/index.php?option=com_docman\&view=download\&a lias=104251-rces007-18\&category_slug=dezembro-2018-pdf\&Itemid=30192. Acesso em: 10 jun. 2019.

BRASIL. Ministério da Educação. Parecer CNE/CES no 635/2018. Revisão das Diretrizes Curriculares Nacionais do curso de graduação em Direito. Disponível em: https://www.migalhas.com.br/arquivos/2018/10/art20181030-11.pdf. Acesso em: 10 jun. 2019. 
BRASIL. Ministério da Saúde; Conselho Nacional de Saúde. Resolução no 466, de 12 de dezembro de 2012. Diretrizes e normas regulamentadoras de pesquisas envolvendo seres humanos. Diário Oficial da União da República Federativa do Brasil, v. 150, n. 112, 2013.

CARVALHO, J. M. A construção da ordem: a elite política imperial; Teatro de sombras: a política imperial. 2.ed. Rio de Janeiro: Civilização Brasileira, 2003.

CHUEIRI, Vera Karam de. Direito e literatura. In: BARRETTO, Vicente de Paulo (org.). Dicionário de filosofia do direito. Rio de Janeiro: Renovar; São Leopoldo: Unisinos, 2006. p. 233-235

DUARTE, Isabel Cristina Brettas; MADERS, Angelita Maria. Crises e Desafios do Ensino Jurídico Frente à Crescente Complexidade das Relações Sociais. Revista Brasileira de Educação e Cultura, Centro de Ensino Superior de São Gotardo, São Gotardo, n. XIV, p. 01-21, jul-dez 2016. Trabalho 01.

DWORKIN, Ronald. Uma questão de princípio. São Paulo: Martins Fontes, 2017.

ESPINDOLA, A.; SANGOI, B. O senso comum teórico do jurista e a arte de reduzir cabeças: em busca de um aporte metodológico para o ensino jurídico. Revista de Direito da Faculdade Guanambi, Guanambi v. 3, n. 01, p. 37-56, 1 ago. 2017.

ESPINDOLA, A.; SEEGER, L. 0 ensino jurídico no brasil e o senso comum teórico dos juristas. Revista de Direito da Faculdade Guanambi, Guanambi, v. 5, n. 02, p. 92-120, 4 mar. 2018.

GADAMER, Hans-Georg. Verdade y método, I. Tradução: Ana Agud Aparicio e Rafael de Agapito. 10. ed. Salamanca: Sígueme, 2003.

GHIRARDI, José Garcez; OLIVEIRA, Juliana Ferrari de. Caminhos da superação da aula jurídica tradicional: papel das instituições de ensino. Revista Brasileira de Estudos Políticos, Belo Horizonte, v. 1, n. 113, p.379-404, dez. 2016.

GHIRARDI, José Garcez (org.). Métodos de ensino em direito: conceitos para um debate. São Paulo: Saraiva, 2009. 
GODOY, Arnaldo. Direito e literatura: os pais fundadores: John Henry Wigmore, Benjamin Nathan Cardozo e Lon Fuller. In: CALVO GONZÁLEZ, José (dir.). Implicación derecho literatura. Granada: Comares, 2008. p. 41-70.

GOMES, C. T. M.; TASSIGNY, M. M. A crise do ensino jurídico no brasil sob a perspectiva do uso do direito alternativo. Prisma Jur. São Paulo, v.17, n.1 p. 159-179, 2018.

HEIDEGGER, Martin. Sobre o Humanismo. In: SARTRE, J.-P.; HEIDEGGER, M. Conferências e escritos filosóficos. Tradução: Ernildo Stein. São Paulo: Abril Cultural, 1973. p. 347-373.

MARTíNEZ, Sérgio Rodrigo. A evolução do ensino jurídico no Brasil. Jus Navigandi, Teresina, ano 10, n. 969, 26 fev. 2006. Disponível em: http://www. egov.ufsc.br/portal/sites/default/files/anexos/29074-29092-1-PB.pdf. Acesso em: 13 ago. de 2019.

NEVES, S. T. A. 0 ensino do direito e a matriz positivista. Revista Em Tempo, [S.l.], v. 7, n. 7, p. 76-89, mar. 2010.

OST, François. Contar a Lei: as fontes do imaginário jurídico. São Leopoldo: Unisinos, 2009.

SCHOPENHAUER, A. A arte de escrever. Porto Alegre: L \&PM, 2012.

SCHWARTZ, Germano; MACEDO, Elaine. Pode o direito ser arte?: respostas a partir do direito \& literatura. In: XVII ENCONTRO PREPARATÓRIO PARA O CONGRESSO NACIONAL DO CONPEDI, 2008, Salvador. Anais do Conpedi. Florianópolis: Fundação Boiteux, 2008. p.1013-1031.

SHECAIRA, Fábio Perin. A importância da Literatura para juristas. Anamorphosis: Revista Internacional de Direito e Literatura, v. 4, n. 2, p.357-377, dez. 2018.

STRECK, Lênio Luiz. Perspectivas hermenêuticas do ensino em tempos de "S.O.S. Direito" (direito plastificado-pasteurizado). Existe um Direito Humano fundamental a um ensino jurídico adequado ao Estado Democrático de Direito?. In: NALINI, José Renato; CARLINI, Angélica. Direitos humanos e formação jurídica. Rio de Janeiro: Forense, 2010. 
TRINDADE, André Karam. Kafka e os paradoxos do direito: da ficção à realidade. Revista diálogos do direito, [S.l.], v. 2, n. 2, p. 225-257, nov. 2012.

TRINDADE, André Karam; BERNSTS, Luiza. 0 estudo do "direito e literatura" no Brasil: surgimento, evolução e expansão. Anamorphosis - Revista Internacional de Direito e Literatura, n. 3, v. 1, p. 225-257, 2017.

UNIVERSIDADE DE FORTALEZA. Projeto cidadania ativa. Disponível em: https://www.unifor.br/projeto-cidadania-ativa. Acesso em: 15 jun. 2019.

WARAT, Luis Alberto. 0 monastério dos sábios: o sentido comum teórico dos juristas. In: WARAT, Luis Alberto. Introdução geral ao direito: a epistemologia da modernidade. Porto Alegre: Sergio Antonio Fabris Editora, 1995.v.II, p. 57-99.

WARAT, Luis Alberto et al. Territórios desconhecidos: a procura surrealista pelos lugares do abandono do sentido e da reconstrução da subjetividade. Florianópolis: Boiteux, 2004.

Recebido em: 31-08-2019

Aprovado em: 11-12-2019 


\section{Monica Mota Tassigny}

Doutora em Sócio-Economie du développement - Ecole des Hautes Études en Sciences Sociales; doutora em Educação pela Universidade Federal do Ceará; mestre em Educação pela Universidade Federal do Ceará; professora titular da Universidade de Fortaleza - UNIFOR, do Programa de Pós-Graduação Direito Constitucional e do Programa de Pós-Graduação em Administração. Membro titular da Academia Metropolitana de Letras de Fortaleza; membro efetivo da Câmara de Assessoramento Técnico-Científico da Funcap. E-mail: monicatassigny@unifor.br

\section{Lívia Chaves Leite}

Mestranda bolsista pela Universidade de Fortaleza - UNIFOR; pesquisadora do grupo de pesquisa Estado, Política e Constituição (Cnpq/Unifor). E-mail: liviachaves_@hotmail.com Érica Valente Lopes

Mestranda em Direito Constitucional pela Universidade de Fortaleza - UNIFOR (2019); pesquisadora do Grupo de Pesquisa CNPQ Relações Econômicas, Políticas, Jurídicas e Ambientais na América Latina - REPJAAL; advogada. E-mail: valente.erica@gmail.com

Universidade de Fortaleza - UNIFOR

Av. Washington Soares, 1321 - Edson Queiroz, Fortaleza - CE, 60811-905 